\title{
Reflex Respiratory Effects from Intermittent Stimulation of Vagus and Superior Laryngeal Nerves
}

Charles Hillenbrand

Loyola University Chicago

Follow this and additional works at: https://ecommons.luc.edu/luc_theses

Part of the Physiology Commons

\section{Recommended Citation}

Hillenbrand, Charles, "Reflex Respiratory Effects from Intermittent Stimulation of Vagus and Superior Laryngeal Nerves" (1937). Master's Theses. 584.

https://ecommons.luc.edu/luc_theses/584

This Thesis is brought to you for free and open access by the Theses and Dissertations at Loyola eCommons. It has been accepted for inclusion in Master's Theses by an authorized administrator of Loyola eCommons. For more information, please contact ecommons@luc.edu. (c) (i) () $\ominus$

This work is licensed under a Creative Commons Attribution-Noncommercial-No Derivative Works 3.0 License. Copyright (c) 1937 Charles Hillenbrand 
IOYOLA UNIVERSITY

SCHOOL OT MEDICINE

\begin{abstract}
REFIEXX RESPIRATORY FFFECTS FROM INPERNITTENT STIMULATION OF THE VACUS AND SUPERIOR IARYIGEAL NIRRVES
\end{abstract}

\author{
A THESIS \\ SUBMITTED IN PARTIAL FULIPILIMENI \\ OF THE REQUIREMATIS FOR THE DFGREE OF \\ MASTER OF SCIFACE \\ IN \\ IOYOLA UNIVERSITY \\ IN \\ THE DEPARTMENT OF \\ FHYSIOIOGY AND PHARMACOLOGY \\ BY \\ CHARIESS HIIITEIRRAND \\ CHICAGO, IILINOIS \\ 198637
}


I was born in Chicago, Illinois, on November 2, 1912. My elementary and secondary education was obtained at St. Miehael Central High Sohool, in the same eity. Following this, two years were spent in a premedical course in the College of Arts and Selences of Ioyola University. I then entered the School of Medicine where after two rears of preclinical study I was given a one year's teaching fellowship in the department of physiology and pharmacology. During this fellowship the work described in the following thesis was performed. 
These researches were performed in collaboration with Dr. T. E. Boyd, professor and head of the depertment of physiology and phermacology: to Dr. Boyd for his characteristic klndness and patient instruction, the humble gratitude of one whose way along the soientific path would hare been meh more obscure and stony without him.

I also indebted to Dr. H. N. Ets of the same department for his advice in regerd to the use of anesthetics. Dr. R. D. Templeton, Dr. I. F. Eumon, Jr., Mr. Jacob Giardina, and Mr. Walter Cokely have all been extremely generous with their time and assistance. I take this occasion to extend to them my sincere appreciation. 


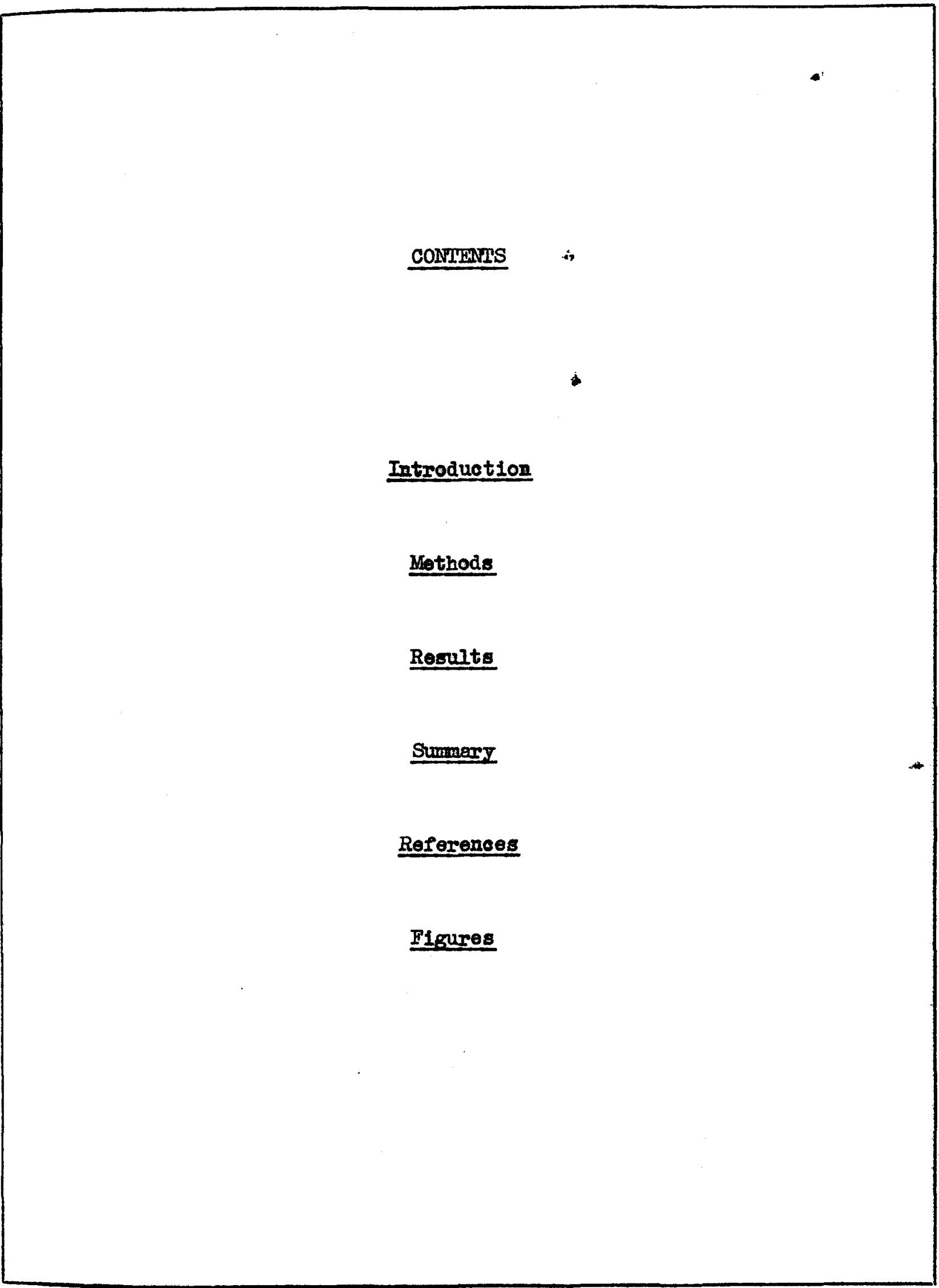




\section{Introduction}

Section of the ragi usually produces two changes in the character of the respiration: an increase in the depth and duration of inspiration, and a decresse in frequency. These chenges are attributed to the loss of a reflex from the lungs, the afferent pathways of wich are the vag1. It is generally agreed that these nerves In some way not only limit the depth of the inspiration, but also maintein an accelerator effect on the respiratory rhythm.

The first of these effects is clearly due to inhibitory afferent fibers in the vagi which are stimulated by the inflation of the lungs. The mechanism by which the breathing is accelerated, howerer, is still a metter of controversy. Hering and Breuer (1868) believed that a set of fibers stimulated by deflation of the lungs initiated the next inspiration. There is muoh evidence indicating that fibers In the vagi do exist which heve a reflex inspiratory or accelerator effeet. They are, however, exclted only by forced deflation, and they have not been shown to be active in ordinary breathing. 
A second theory suggested by Head (1889) end supported by Adrian (1933) assumes that the inhibitory fibers of the ragi not only limit the depth of respiration, but indirectly control the frequency. According to this view, the respiratory center has an inherent rhythm of its own, and if it is allowed to discharge campletely will produce a slow frequency. When the ragi are intact, each inspiration is cut short, and the center does not discharge fully. Its recovery time is correspondingly shortened, and the next inspiration sets in more quickly than it would in the absence of the inhibitory influence.

A third theory recently advanced by Hemmouda and W1lson (1932, 1935a, 1935b) infers that breathing is controlled by two sets of fibers, one inhibitory which affects the depth, the other augmentor which affects the rate and is functionel throughout the respiratory cycle.

Continuous tetanization of the central stump of the ragus, in anesthetized animels, ordinerily causes expiratory stendstill (figure 2). If Head's hypothesis is correct, it should be possible to accelerate the respiration in a vagotomized animel by intermittent stimli applied to the vagus. The stimili should be so timed as to interrupt each inspiration at a moderately advanced stage. Under these conditions acceleration might be expected through 
the indirect action of the inhibitory fibers alone; this acceleration would be even enhanced if eugmentor fibers were simultaneously activated.

Sererel Investigators (most recently Gesell and Moyer, 1935) have found that with periodic stimulation of the vagus the respirations fall into the fixed rhythm of the stimulus. We have conflrmed this observation in a number of our experiments. Little effort seems to hare been made by others, howerer, to imitate the normal periodic activity of the inhibitory fibers. Adrian (1933) found that the frequency of impulses (and the number of active fibers) varied with the degree of inflation of the lungs. During inspiration, therefore, the center is presumebly subjected to gradually increasing inhibition, from which it is automatically released as the lungs are deflated. Such a mechanlsm would never subject the center to inhibition of greater intensity than is required to stop the inspiration in progress. We have not ettempted the difficult foat of imitating, artificially, this natural gradation. The ragus was subjected to unform tetanization so long as the lungs were inflated beyond a fixed point. The effects on respiration, however, seem to agree with the interpretation of Head and Adrian. 


\section{Mothods}

Dogs were used, anesthetized with barbital-sodium. The dose usually veried from 0.25 to 0.30 gram perikilogram of body weight, but sometimes more wes administered to quiet irregular respiration. Both vagi were sectioned in the inferior cervical region, and the central stump of one was drawn lnto a molst chember consisting of a block of bakelite with a longitudinal groove just wide enough to accomodate the nerve. The stimulating electrodes were silver wires lying aoross the bottom of the groove. Drying of the nerve was prevented by a vaseline-sealed glass plate which formed the roof of the chamber.

The respirations were recorded by means of a bress trocar pessed through the thorax just behind the sternum, with perforations opening into the pleural carity. One end of the tube was closed; the open end communicated with a tambour to which chenges In intrapleural pressure were trensmitted. The lever of the tambour carried in addition to the writing point a platinum wire with a Iree end projecting toward a mercury cup below. With the key $K_{1}$ olosed (figure 1) the inspiratory down stroke of the tambour made contact in the primary circuit of a Harvard inductorium, arranged for tetanizing stimuli, or of a photo-electric cell stimulator of Humon. The vagus was thus stimulated until expiration broke the 
contact. The nerve was left at rest except when the lungs were inflated beyond a point determined by the level of the meroury contact. For brevity, we shall simply use the term "intermittent stimulation" in referring to this method. Closure of the key $K_{2}$, placed in perallel with the platinum-mercury contact, permitted continuous tetenization when desired. Exctpt in figare 9 where the reverse obtains, downstroke records inspiration and upstroke expiration in the tracings presented.

Ordinarily the stimulus was first adjusted to a strength just sufficient, when applied continuously for from five to ten seconds, to cause expiratory stendstill. The same stimulus was then used intermittently.

\section{Results}

Figure 2 shows the effect of continuous and intermittent stimulation of the left vagus. A stimulation just sufficient to cause expiratory standst1ll when continuous produces an acceleration in rate and a reduction in amplitude when intermittent. The acceleration always occurs colncident with the first inhibited respiration, and is lost when the stimulation is stopped. For this reason, it is highly improbable that it is due to chemical stimulation of the center from reduced pulmonary ventilation. Acceleration from such 
a cause would be expected to develop more or less gredually, with some delay, as does the slight rise of arterial pressure seen in figure 2.

While the reduction in emplitude was almost invariably obtained with all strengths of stimulation above thpeshold, it is of interest to note that in a number of dogs used the prolonged inspiration deseribed by Gesell and Moyer (1935) was observed (figure 3). In a series of ten or twelve cycles one or two inspirations (most often the first) would be of this type. We have not attempted to interpret this anomalous respiration. In one animel, the inspiratory response was abolished by the administration of more of the anesthetic. With the others, this was not tried.

The acceleration described wes obtalned in all animals but one. It is most constant, however, when the intermittent stimuli are relatively weak. With stronger stimull the respiration becomes irregular, and with still stronger stimuli the rhythm is slowed (Ilgure 4). In three cases an Intermediate position of the secondary coll was found at which neither continuous nor intermittent stimulation of the vagus produced any visible effect upon the respiration. Tests with the oscillograph showed that the stimulating aircuit was 1ntact. Stronger and weaker stimull had the usuel effects.

It is probable that all of the afferent flbers of the vagus 
were activated by some of the stronger stimuli used. An inference could be made, therefore, that while the reduction in amplitude was due to the inhibitory I1bers, the increase, in frequency was caused by the simulteneous stimulation of the augmentor fibers. This seems unlikely to us for sereral reasons. First, Hamouda and Wilson (1935a) conclude, from the resistance of the augmentor fibers to pressure blook, that they are of relatively small size. If so, they should have a threshold higher then that of the inhibitory fibers, and it should be possible to obtein the reduotion of amplitude without the acceleration. Actually, as already stated, the weakest stimull capable of depressing the inspiration are the most effective in acelerating. Second, the increase in rate varies with the position of the mercury contact, that is, with the stage at which the inspirations are arrested (figure 5). The greater the reduction in emplitude, the greater the incresse in frequency. Such a relationship seems to be implicit in Head's theory; it is difficult to explain if the two effects are attributed to different groups of afferent fibers.

We suggest the following explanation: that inhibition if just strong enough to cut short inspiration has a brief effect, which does not continue far into the expiratory stage. The center is thus allowed to recover early following incomplete discharge, as Head believed. Stronger Inhibitory stimuli have a more sustained 
action, and this is carried into the recorery phase of the respiratory center. The onset of the next inspiration is thus deleyed. It is true that expiration automatically breaks the contact, and that this occurs more promptly with strong than with weak stimuli (figure 4), but the period of stimulation is never reduced below a minimum set by the reflex time and by the inertia of the mechanical system.

We have also studied the effects of varying the duration of stimilation of the sectioned vagus. Excitation of the nerve for a period of 0.45 second is incapable of arresting the breathing unless applied very late in inspiration. Stimulation of one second is effective at an earlier stage of inspiration, while one of two seconds is effective still earlier. From this it is clear that as the inspiration progresses it becomes more refractory to Inhibition. Two explanations for this behavior may be possible. First, the respiratory center may be more sensitive to inhibition in the terminal than in the initial stages of inspiration. Second, the inhibitory impulses ascending the vagus may reinforce the proprioceptive impulses originating in the muscles of inspiration which have a similar action.

Hamouda and Wilson (1935b) compared the respiratory effects of stimulating the vagus and superior laryngeal nerves. Both 
normally cause expiratory standstill. When the nerves were locally cooled, the reflex from the superior laryngeal was simply lost at about elght degrees, with no effect at lower temperatures. The inhibitory effect of the vagus was also lost at the same temperature, but an accelerator effect was obtained on further cooling of the nerve. The authors conclude that "augmenthation of the rate of breathing cannot under any conditions be due to the stimulation of fibers carrying inhibitory impulses." We feel that this conclusion rests on insufficient evidence. In the first place, Hammouda and Wilson base their argument upon continuous stimulation of the nerves, elthough they seem to agree with the comon view that the normal activity of the inhibitory fibers is intermittent. Again, even if it had been proved that the superior laryngeal nerve cannot under any condition increase the respiratory rate, it would not necessarily indicate that the inhibitory fibers of the vagi are incapable of doing so.

While continuous tetanization of the two nerves produces similar effects, especially when begun during the expiratory phase, intermittent stimilation roveals striking differenoes in their actions. The vagus (Itgure 2) arrests inspiration abruptly and completely, whereas the superior leryngeal does not. Instead, stimulation of the superior laryingeal causes the animal to expire just sufficiently to break the contact; inspiration is then re- 
sumed (figure 6). The lungs are not deflated to their normal expiratory level until after one or more ebortive attempts to finish the interrupted inspiration. In some cases, the frequency has been accelerated. More often, however, it is decreased, beceuse each inspiration is drawn out into a series of small alternating inspiratory and expiratory movements. These, if counted as separate cycles, greatly augment the respiratory rate.

Stimulation of the superior laryngeal nerve at various stages of inspiration (figure 7) at no time produces abrupt termination of the movement in progress. Although it is easier to inhibit the inspiration in a late than in an early stage, at no time is it possible to terminate it in the seme way as can be done by stimulation of the ragus. When the stimulus is applied early, there may be six or seven abbreviated respirations, ending in a period of spasm with an inspiratory direction. These effects ere obtained with a wide range of stimulus strength, in animals with and without tracheotamy; and they are not materially changed by deepening the anesthesia almost to the point of respiratory failure.

Figure 8 shows the effect of varying durations of stimulation of the superior laryngeal. Stimulation at any point in the inspiration does not terminate the movement, even when the excitation is as long as two seconds. 
This behavior of the superior laryngeal nerve is quite remarkable in view of the powerful expiratory effect usually escribed to that nerve. Although it is possible to induce expiration if the stimulus is maintained, it is evident that the inhibitory fibers of the vagus and of the superior largngeal do not affect the respiratory center in exactly the same manner.

Forcible inflation of the lungs at room temperature ordinarily causes inhibition of the respiration. Hanouda and Wilson claim that if the vagus nerves are cooled to around eight degrees, this reflex is reversed, that is, acceleration is obtained. We have repeated experiments of this kind and in a few eases have been able to confirm these authors. Hamouda and Wilson further maintain that this reversal phenomenon is abolished by section of the ragi. The tracings which they publish in support of this observation, however, clearly show an acceleration of the respiratory rate. We have repeated these experiments. Figure 9 shows an evident increase in the frequency of breathing induced by inflation after bilateral vegotomy. It would appear, then, that the respiratory augmentation seen in these experiments is quite independent of the intact or sectioned ragi. The cause of these changes has not been investigated, but it possibly lies in the vescular disturbances brought about by the conditions of the experiments. 


\section{Summary}

(1) A stimulating cirouit, controlled by changes in the intrapleural pressure of an experimental animal, is described. Contact is made at any desired stage of inspiration and broken at the corresponding stage of expiration.

(2) Stimulation of one of the central ends of the divided vagi in dogs anesthetized with barbital-sodium decreases the amplitude of inspiration.

(3) The respiratory frequency is increased by stimuli of moderate strength. Very strong shocks cause irreguler slowing.

(4) The degree of acceleration verles with the stage at which the inspirations are inhibited. The greater the reduction of ampli- tude, the greater the increase in frequency.

(5) Stimulation of the superfor laryngeal nerve during inspiration cuts short the movement, but one or more abortive attempts are made to complete it. These effects indicate an apparent difference between the inhibitory fibers of the vagi and of the superior laryngeal nerves.

(6) It is possible in some cases to accelerate the respiratory Irequency by intermittent stimulation of the superior leryngeal. 
(7) Acceleration of the respiration can be obtained by means of inflation after section of the ragus nerves.

\section{References}

Adrian, E. E. J. Physiol. 79:332, 1933.

Gesell, R. and C. Hioyer. Quart J. Exper. Physiol. 25:1, 1935.

Haumouda, M. and W. H. Wilson. J. Physiol. 74:81, 1932.

J. Physiol. 83:292, 1935.

J. Physiol. 85: 62, 1935

Head, H. J. Physiol. 10:279, 1889.

Hering. Sitzungsberichte d. Wien. Akad. d. Wist., math-naturw. $\mathrm{K} 1 ., 57: 672,(2), 1868$. 


\section{Figures}

Figure 1. Apperatus for the continuous and intermittent stimilation of the ragus and superior leryngeal nerves.

Figure 2. Male dog, $20 \mathrm{kilos}, 6.0$ grams barbital-sodium. Upper record, erterial pressure (oerotid); lower, respiration. Continuous followed by intermittent stimulation of the central stump of the left vagus. Primary circuit, 6 volts; secondary coil at $10 \mathrm{~cm}$.

Figure 3. Male dog, $11.6 \mathrm{kilos}, 2.9$ grams barbital-sodium. Intermittent stimulation of the left vagus. Primary circuit, 6 volts; secondary coil at $7 \mathrm{~cm}$.

Figure 4. Male dog, $9 \mathrm{kilos}, 3.6$ grams barbital-sodium. Intermittent stimulation of the right vagus, mercury contact at a constant level. Primery circuit, 6 rolts; A, secondary coll at $10 \mathrm{~cm} ., 45^{\circ} ; \mathrm{B}$, at $8 \mathrm{~cm} . ; \mathrm{C}$, at $2 \mathrm{~cm}$.

Figure 5. Female dog, $19 \mathrm{kilos}, 11.2$ grems berbital-sodium. Intermittent stimulation of the right vagus. Primary circuit, 6 volts; secondary coll at $10 \mathrm{~cm} ., 10^{\circ}$. Nercury cup progressively lowered from $A$ to $D$.

Figure 6. Female dog, $7.7 \mathrm{kilos}, 2.2$ grams berbital-sodium, 
30 mem. morphine sulphate. Both veg1 sectioned. Stimulation of right superior laryngeal. Primary ciroult, 6 volts; secondary coil at $10 \mathrm{~cm} ., 45^{\circ}$. B, continuous tetanization; $A$ and $C$, intermittent stimulation, mercury oup lower at $C$.

Figure 7. Same dog as in figure 2. Intermittent stimulation of right superior laryngeal. Primary cirouit, 6 volts; secondery coil at $8 \mathrm{~cm}$. Mercury cup progressively lowered from $A$ to $D$.

Figure 8. Female dog, 2316 kilos, 7.1 grems berbital-sodium. Both vagi sectioned. Showlng different durations of stimulation of right superior laryngeal. $0.25 \mathrm{volt;} 120 /$ second; I sigma. A, 0.45 second; $B, 1.0$ second; C, 2 seconds.

Figure 9. Male dog, 9 kilos, 2.7 grams barbital-sodium. Effects of forcible inflation. A, vagi intact; B, vagi sectioned. 

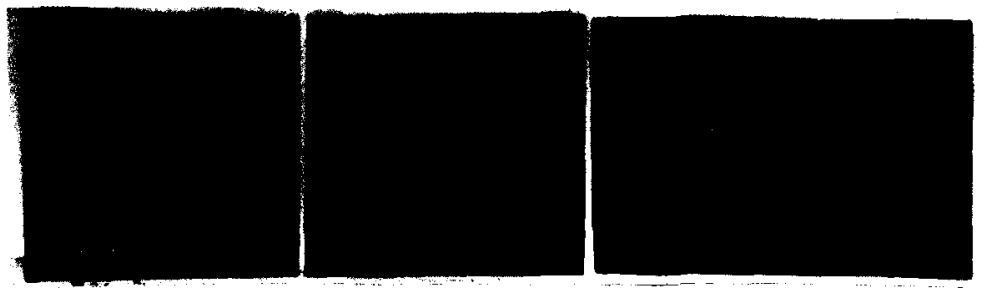

Figure 4

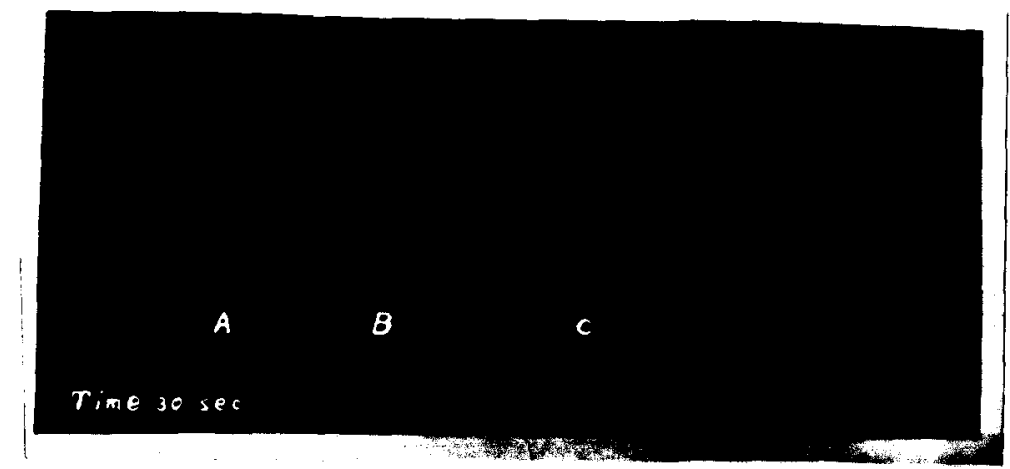

Figure 5

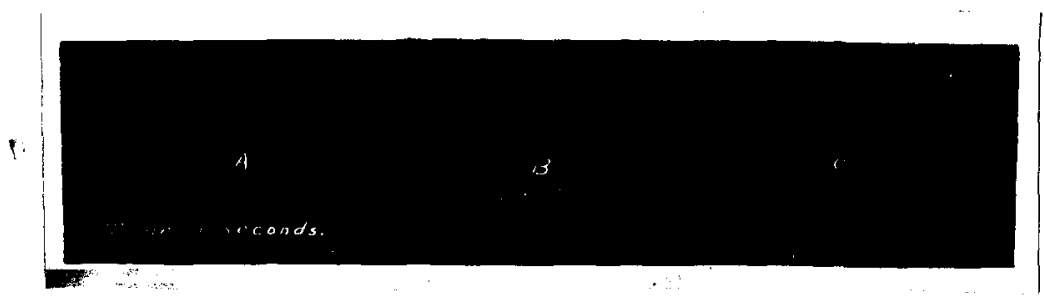

F1gure 6

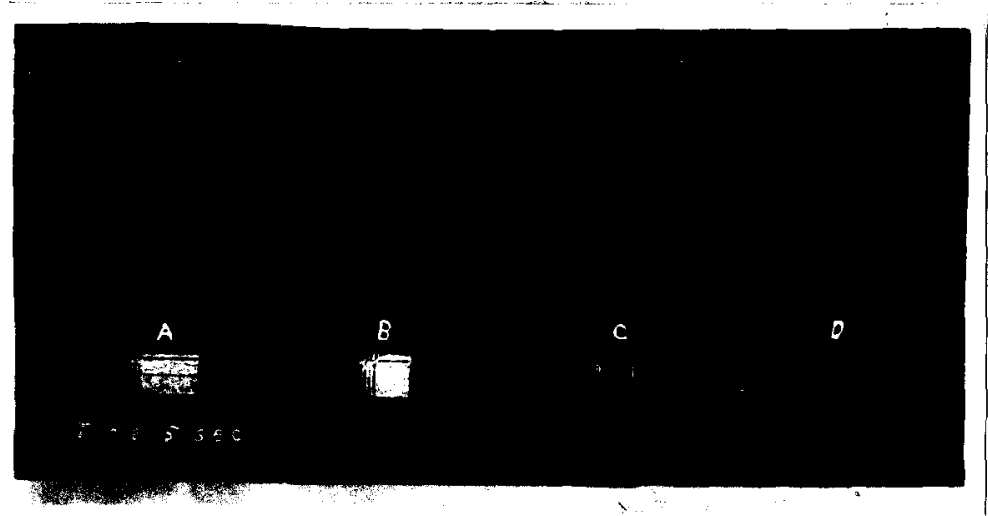

Figure 7 


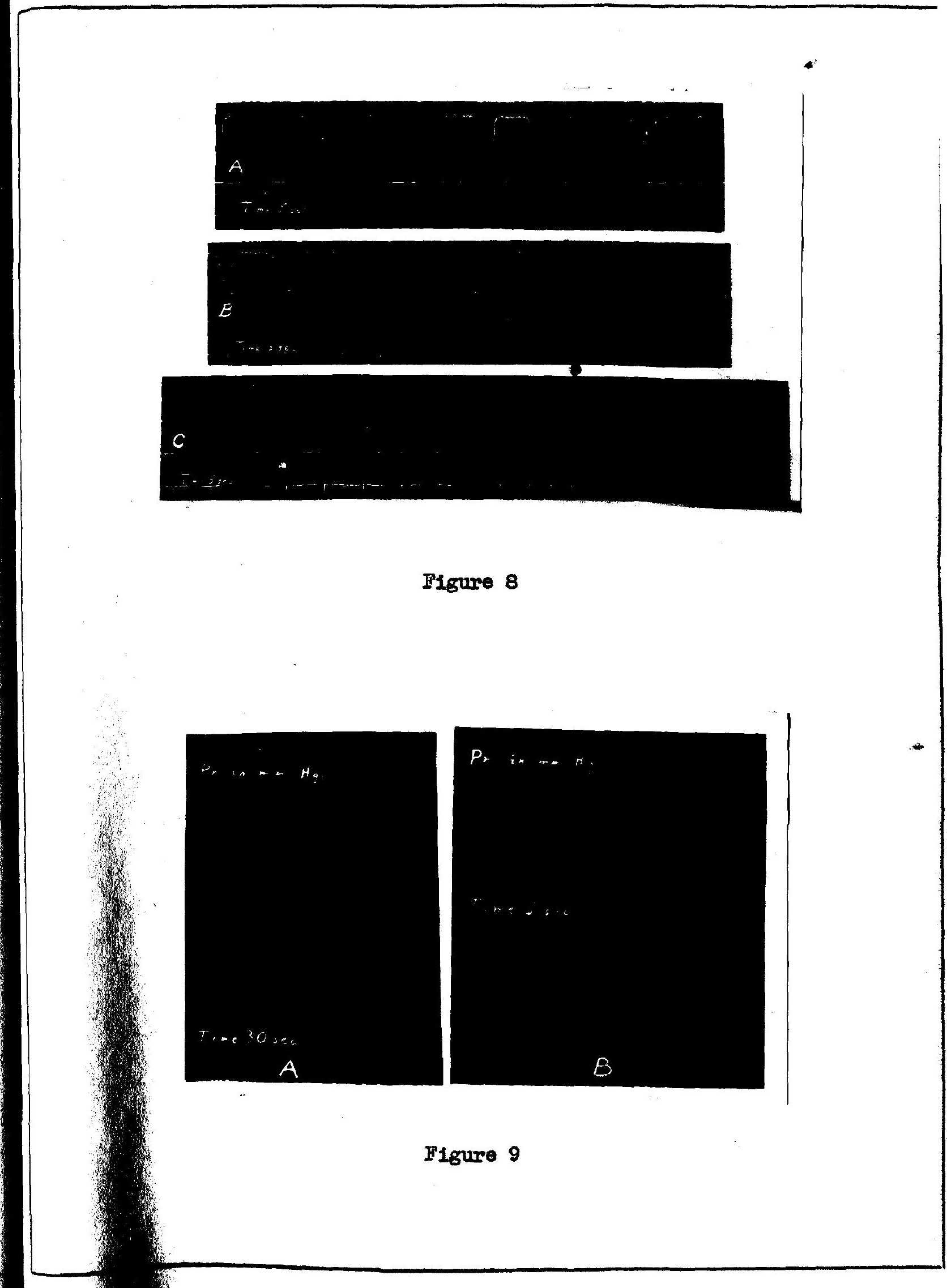

Figure 9

Figure 8

B 
